Volume 10, No.4, July - August 2021

International Journal of Advanced Trends in Computer Science and Engineering

Available Online at http://www.warse.org/IJATCSE/static/pdf/file/ijatcse071042021.pdf

https://doi.org/10.30534/ijatcse/2021/071042021

\title{
Barangay Profiling System with Analytics
}

\author{
Bernard Jacobe ${ }^{1}$, Mark Lester Pascua², Billy Jay Tumbali ${ }^{3}$, Maria Clarissa Aquino ${ }^{4}$, \\ Maria Visitacion Gumabay ${ }^{5}$ \\ ${ }^{1}$ St. Paul University Philippines, Tuguegarao City, Cagayan, bjacobe@ @spup.edu.ph \\ ${ }^{2}$ St. Paul University Philippines, Tuguegarao City, Cagayan, mlpascua@spup.edu.ph \\ ${ }^{3}$ St. Paul University Philippines, Tuguegarao City, Cagayan, bjtumbali@spup.edu.ph \\ ${ }^{4}$ St. Paul University Philippines, Tuguegarao City, Cagayan, caquino@spup.edu.ph \\ ${ }^{5}$ St. Paul University Philippines, Tuguegarao City, Cagayan, mvgumabay@ spup.edu.ph
}

\begin{abstract}
This study aimed to develop a Barangay Profiling System with Analytics for Barangay Pallua Sur, Tuguegarao City. It aimed to provide systematic profiling system which can the authorized users easily manage residents' profile, generate statistical reports, and the provision of updating the records. The researchers utilized qualitative approach using descriptive research design and systems development in collecting, analyzing the data and the design and development of the system. The researchers conclude that the developed system automates the profiling of all residents in the barangay. It stores data electronically thus, records are more organized, and also it provides an access of the information needed by the barangay. Reports needed with statistical analysis can be easily generated.
\end{abstract}

Key words: Analytics, Managing Records, Profiling, Systematic

\section{INTRODUCTION}

The necessity to focus on the societal issues of every barangay is a relevant aspect that needs awareness from the person in authority. These are said to be the most essential responsibilities of every barangay officials in the Philippines. Managing, monitoring and tracking of the most important information of each household in the barangay can be realized with the use of technology. Majority of the barangays in Tuguegarao City have their own computer units used for data processing and spreadsheets. The records of each household are kept in a file cabinet. The barangay personnel find in tedious to manage, monitor and track the records. Profiling information of each household using a system could make the personnel more productive and can give a better service to the community.

The Barangay Profiling System with analytics organizes, categorizes records and provides information of each resident and statistics according to gender and age bracket. The system also generates barangay clearance of residents whenever they apply for it.

The researchers developed the system to help the barangay officials and personnel to have better form of managing, monitoring and tracking residents' information, Also, have an easy access of the information details of each resident and generate quickly the reports needed.

According to Lacasandile, A. D., Abisado, M. B., Labanan, R. M., \& Abad, L. P. (2020, August), profiling each household in the community using information and communication technology could achieve good governance through E-government as its core. Once profile data are aggregated, essential information could provide statistics in labor and employment, family income and expenditures, demography by population and age, water and sanitation, type of housing and education.

Claire Ong Carpio (2020) states that the Barangay Management System or e-barangay is a web-based management system which shall reinvent barangay management from a traditional and centrally dependent unit towards a more inclusive and citizens-oriented scheme. It essentially aims to streamline existing administrative processes in terms of requesting documents, filing complaints, and generating apt and accurate local statistics. The researchers have adopted the prototype methodology in the development of the system. It focuses on creating and testing system features, graphical user interface and scheduling iterations.

According to Bautista, R. M. (2015), the advent of modern technology opens wider opportunities for barangays to serve their constituents better through computerization of the documents they provide such as barangay clearance, certificate of indigency, letter of recommendation, annual report, and others. Motivated by the vision of empowering this self-governing political system digitally, the researchers aimed to determine the advantages of ICT and develop an office management system that will hasten the transactions performed and documents provided by the barangays. The developed system was designed to be accessed only by the authorized users to ensure the integrity of all transactions. 


\subsection{Conceptual Framework}

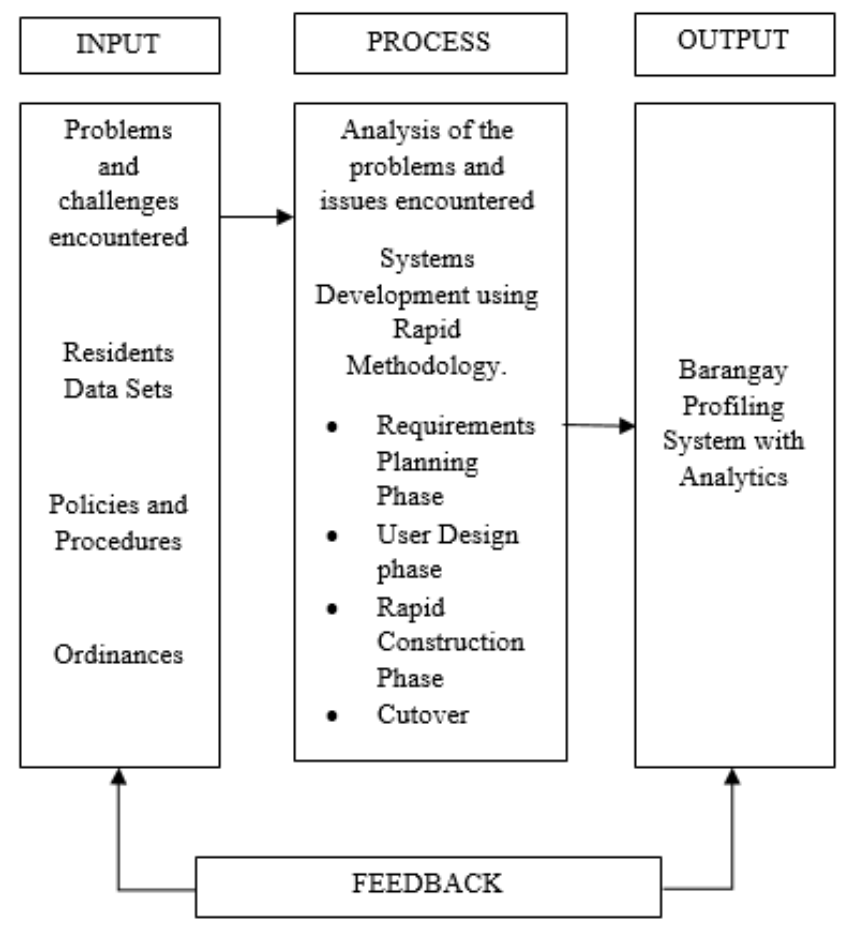

Figure 1: Paradigm of the Study

The paradigm illustrates the input and processes to achieve the desired output of the study.

\subsection{Statement of the Problem}

This study aimed to develop a barangay profiling system with analytics.

More specifically, the study sought answers to the following:

1. What are the problems and challenges encountered by the participants in managing residents' profile?

2. What system can be developed to address the problems and issues encountered by the participants?

3. What enhancement can be done to improve the developed system?

\section{METHODOLOGY}

\subsection{Research Design}

This study employed a qualitative approach using descriptive research design and systems development in collecting, analyzing the data and the design and development of the system. The interview method was utilized to collect necessary information to determine the problems and issues encountered by the participants in the barangay.

\subsection{Participants of the Study}

The participants of the study were composed of the barangay officials and secretary of Pallua Sur, Tuguegarao City. The researchers made use of random sampling method.

Table 1: Participant of the Study

\begin{tabular}{|c|c|}
\hline Participants & Population \\
\hline Barangay Officials & 8 \\
\hline
\end{tabular}

\begin{tabular}{|c|c|}
\hline Secretary & 1 \\
\hline Total & 9 \\
\hline
\end{tabular}

\subsection{Instrumentation}

In gathering the necessary data, the study used interview, and substantiated with literature review.

Interview guide. The study used this technique to gather significant facts and information to be utilized in the study.

Interview was conducted to the barangay officials and secretary of barangay Pallua Sur to determine the problems and challenges in managing residents' profile.

\subsection{Data Gathering Procedure}

The researchers prepared a letter of request addressed to the barangay captain to gather related information needed for the development of the barangay profiling system. After accepting the request, the researchers conducted personal interview using available online resources such as Google form, Google meet and MS Teams. Moreover, the researchers also gathered information using literature sources.

\section{RESULTS AND DISCUSSION}

\section{A. Problems and Challenges Encountered by the Participants.}

The common problem encountered by the participants are the following:

- Poor Filling System

- Lack of Systematic Filling or documents/records

- Time consuming in preparation of reports.

- Compilation and Management of documents

- Difficulty in Classifying, Sorting and Searching resident's information.

- Difficulty in generating statistical reports.

Inefficient management of documents and records affects the performance of an organization. This is when records are not well stored or managed accordingly. The personnel in charge of barangay profiling should undergo re-training on file management, an efficient and effective record management system.

The common challenges encountered by the participants are the following:

- Time Management

- Gathering of Relevant Data

- Retrieval of Accomplished forms by the residents

- Updating of Residents' Profile

- Preparation of Reports

- Managing Residents' Profile 


\section{B. The Barangay Profiling System with Analytics}

The Barangay Information System is a local system that can be accessed by two types of end-user. The staff is assigned to encode the residents' information and the administrator for the maintenance of the system. The system stores relevant information of all residents of the barangay. This can be updated, as necessary. The system also has the provision to input barangay complaints and stores them in the database. One of the additional features of the system is to generate barangay clearance needed by the residents for whatever purpose it may serve. This system can generate statistical records such as total population of the Barangay, total registered voters, reported offense against the law, and total of employed and unemployed citizens.

Below are the screen shots of the system.

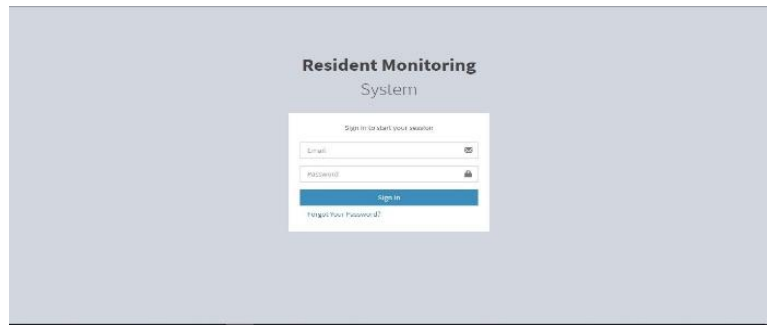

Figure 2: Login Page

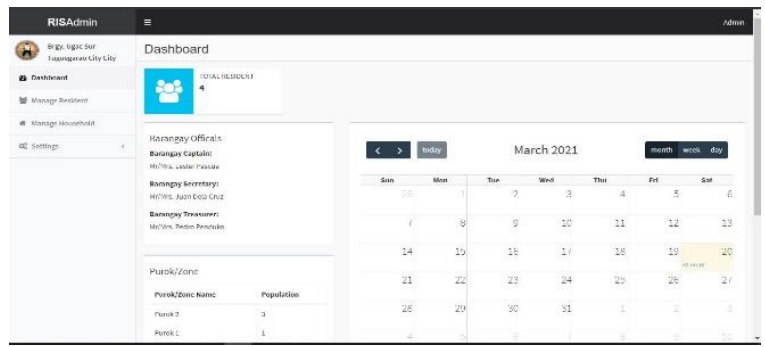

Figure 3: Main Dashboard

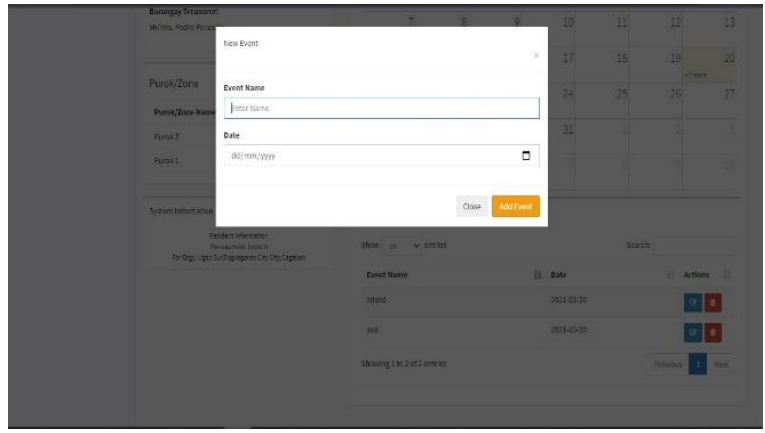

Figure 4: Adding of Events

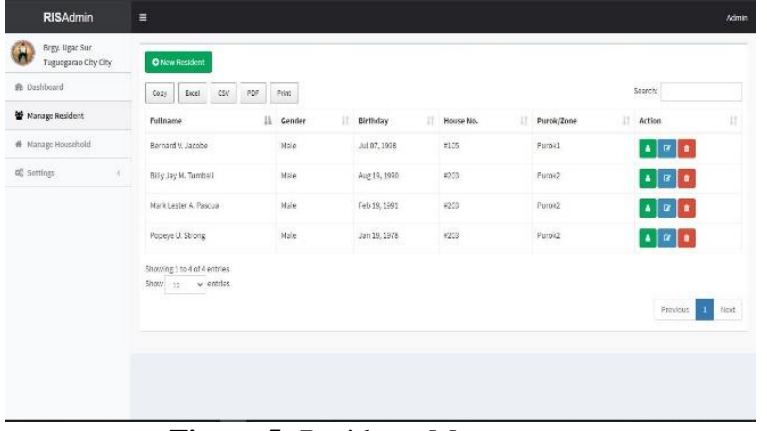

Figure 5: Residents Management

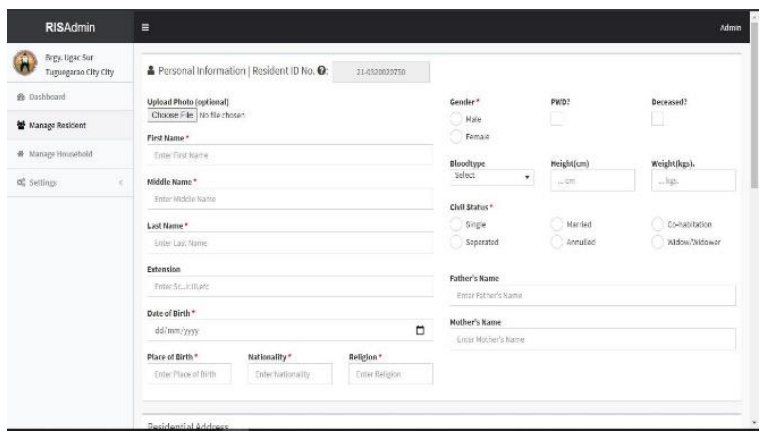

Figure 6: Add Resident

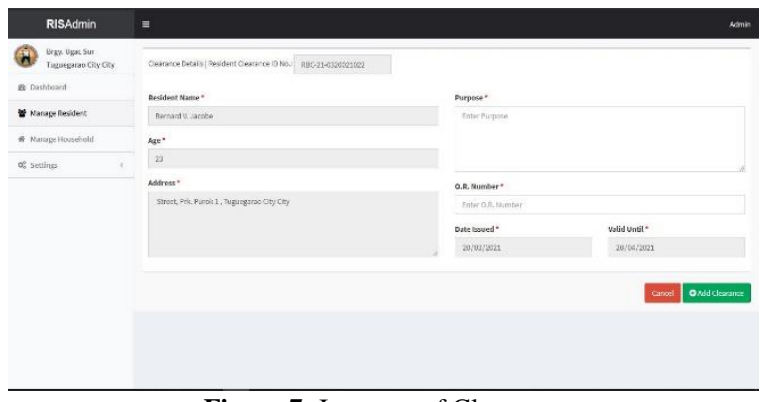

Figure 7: Issuance of Clearance

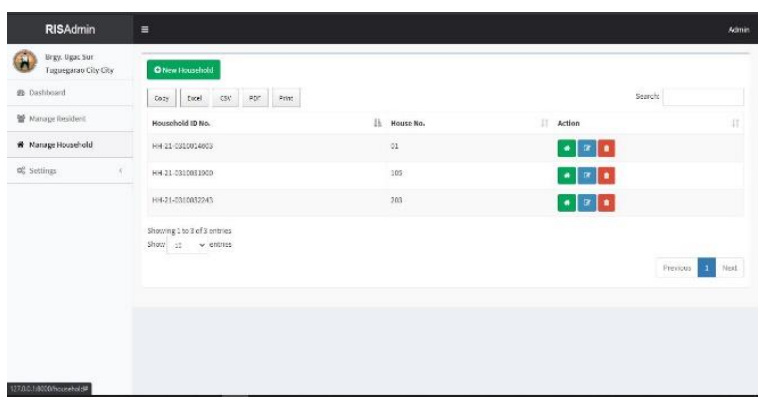

Figure 8: Household Management

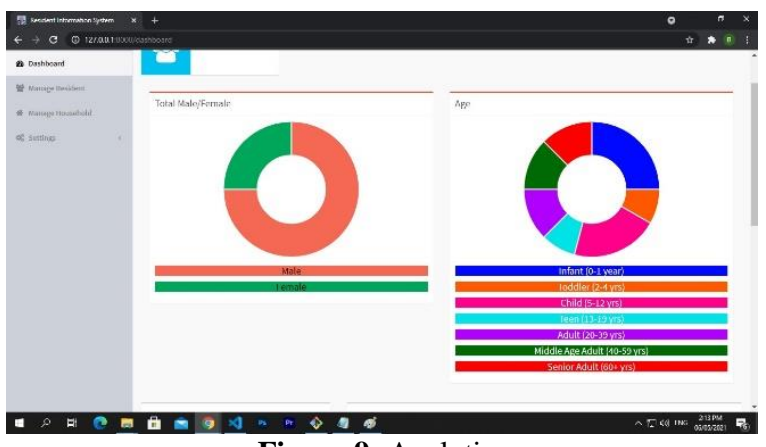

Figure 9: Analytics 


\section{Enhancement of the System}

For future enhancement of the system, the researchers may consider the following:

- May consider embedding the health information for easy tracking and monitoring of health conditions of the residents of the barangay.

- May consider analytics report on health conditions of the residents.

- May also consider module for the use of the barangay treasurer.

- May consider presenting the system to the local government for full implementation to all barangays in Tuguegarao City.

\section{CONCLUSION}

The developed system automates the profiling of all residents in the barangay. It stores data electronically thus, records are more organized, and also it provides an access of the information needed by the barangay. Reports needed with statistical analysis can be easily generated.

\section{RECOMMENDATION}

Based on the findings and conclusions of the study, the following recommendations are presented:

1. The researchers may consider presenting the developed system to the local government for its implementation to all barangays in Tuguegarao City.

2. The researchers may consider giving a training session on the use of the system for proper implementation.

3. The researchers may consider completing the statistical reports needed by the barangay.

4. The researchers may consider developing a module for health information system and financial management for the use of the treasurer.

\section{REFERENCES}

1. Lacasandile, A. D., Abisado, M. B., Labanan, R. M., \& Abad, L. P. (2020, August). Development of an Information-Based Dashboard: Automation of Barangay Information Profiling System (BIPS) for Decision Support towards e-Governance. In 2020 The 4th International Conference on E-Society, E-Education and E-Technology (pp. 68-75).

2. Claire Ong Carpio (2020). Barangay Management System, || International Journal of Multidisciplinary Research and Publications (IJMRAP), Volume 3, Issue 2, pp. 26-32.

3. Bautista, R. M. (2015). Promoting Digital Empowerment through Implementation of Barangay Management System. Bulacan State University. International Journal of Engineering Research and General Science, 3(2 Part 2).

4. Shangri-La Hotel, E. D. S. A. (2004). Establishment of a Barangay Database Information System in Region 10

5. Figueroa, J. Z., Calaguas, J. Q., \&Sicat, A. T. Barangay Constituents Information System (BCIS): Toward Achieving Organizational Efficiency.
6. Salud-Payumo, C., Monsurab, M. P., Magpantay, M., Sanguyo, E., \& Guillo, A. C. (2020). Socioeconomic Profiling of Communities Surrounding Polytechnic University of the Philippines as Basis of Extension Programs. Annals of Tropical Medicine and Public Health, 23, 231-328. 